УДК 378.147

\title{
ПРЕПОДАВАНИЕ ПРОФИЛЬНОЙ ДИСЦИПЛИНЫ ЭЛЕКТРОСНАБЖЕНИЯ С ИСПОЛЬЗОВАНИЕМ ЦИФРОВЫХ ТЕХНОЛОГИЙ
}

\author{
Шевченко Максим Валерьевич \\ канд. с-х. наук, доцент \\ Горбунова Людмила Николаевна \\ канд. с-х. наук \\ Воякин Сергей Николаевич
}

д.т.н., доцент

Проценко Палина Павловна

доцент

ФГБОУ ВО «Дальневосточный государственный аграрный университет»

Аннотация: В статье рассматривается вопрос актуализации рабочей программы по дисциплине «Электроснабжение» для направления 13.03 .02 Электроэнергетика и электротехника в ФГБОУ ВО Дальневосточный ГАУ с внедрением цифровых технологий.

Ключевые слова: актуализация, рабочая программа, индикатор достижения, цифровые технологии, энергетическая отрасль.

\section{POWER SUPPLY PROFILE TEACHING USING DIGITAL TECHNOLOGIES}

\author{
Shevchenko Maxim Valerievich \\ Gorbunova Lyudmila Nikolaevna \\ Voyakin Sergey Nikolaevich \\ Protsenko Palina Pavlovna
}

\begin{abstract}
The article discusses the issue of updating the work program for the discipline "Power supply" for the direction 13.03.02 Electrical engineering and electrical engineering at the Far Eastern State Agrarian University with the introduction of digital technologies in the energy sector in the study of specialized disciplines.
\end{abstract}




\section{ЦИФРОВИЗАЦИЯ КАК НОВАЯ ПАРАДИГМА РАЗВИТИЯ: ВЫЗОВЫ, ВОЗМОЖНОСТИ И ПЕРСПЕКТИВЫ}

Key words: actualization, work program, indicator of achievement, digital technologies, energy industry.

Современный мир быстро меняется. Постоянно появляется что-то новое, что влияет на многие аспекты нашей жизни.

Одной из основных тенденций современной жизни является цифровизация. В правительстве хотят создать «цифровой профиль» каждого россиянина, компании активно внедряют новые разработки, чтобы сократить издержки и опередить конкурентов, а граждане учатся пользоваться новыми сервисами. [1]

Управление системами электроснабжения развивается в сторону расширения областей применения цифровых технологий, такие как система диспетчерского управления, цифровые подстанции и т.д. В Стратегии развития России на период 2018-2024 гг. отмечается, что цифровой переход в электроэнергетике позволит не только сделать более эффективной традиционную энергетическую систему, но и позволит вовлечь «энергообмен распределенной генерации (в том числе на основе возобновляемых источников энергии), систем накопления энергии, устройств и комплексов с регулируемым потреблением для организации разнообразных энергетических сервисов».

Специфика электроэнергетической отрасли состоит в быстротечности и скоротечности происходящих процессов в системах электроснабжения, что предполагает необходимость быстрого реагирования: сбора, обработки большого объема информации и реакции системы на изменения режимов функционирования элементов Единой энергетической системы.

Но чтобы выйти на новый уровень в энергетической отрасли, необходимы не только стратегия и новое (другого уровня) оборудование, но и специалисты, которые смогут работать с учетом новых требований.

Разрыв между требованиями индустрии и выпускниками высшего образования сегодня велик, поэтому необходимо пересмотреть компетенции будущего выпускника с учетом его умения применять цифровые и «сквозные» технологии в отрасли.

В рамках пилотного проекта по внедрению цифровых технологий в энергетике был выбран электроэнергетический факультет. Этот факультет выпускает бакалавров по направлениям: 13.03.02 Электроэнергетика и электротехника, профиль Электрооборудование и электрохозяйство 


\section{ЦИФРОВИЗАЦИЯ КАК НОВАЯ ПАРАДИГМА РАЗВИТИЯ: ВЫЗОВЫ, ВОЗМОЖНОСТИ И ПЕРСПЕКТИВЫ}

предприятий, организаций и учреждений; 35.03.06 Агроинженерия, профиль Электрооборудование и электротехнологии в АПК.

Для примера внедрения цифровых технологий использовалась дисциплина «Электроснабжение», которая является профильной для студентов направления 13.03.02. Данная дисциплина ведется в течении двух семестров на 3 и 4 курсе. Общая трудоемкость дисциплины составляет 7 зачетных единиц.

Целью освоения дисциплины (модуля) «Электроснабжение» является: раскрытие основных принципов построения и функционирования систем электроснабжения для экономичного, надежного и качественного обеспечения потребителей электроэнергией.

Задачи освоения дисциплины (модуля): привитие практических навыков построения электрических систем и сетей; применение методов режимов работы электрических систем и сетей, организация и управление электрическими системами и сетями; основы методологии расчета режимов работы объектов профессиональной деятельности;

Чтобы актуализировать рабочую программу дисциплины под применение информационных и «сквозных» технологий, необходимо добавить ряд задач освоения дисциплины, таких как: принципы построения и работы цифровых систем управления в электроснабжении; выбор наиболее эффективных методов и средств для проектирования цифровых систем управления в электроснабжении; систематизация статистической информации о состоянии систем электроснабжения; выбор наиболее эффективных методов и средств для проектирования цифровых систем управления в электроснабжении.

Реализация этих задач возможна лишь при разработке новых индикаторов достижения профессиональных компетенций. Для дисциплины электроснабжения был разработан индикатор «ИД-2 Прк-2 Применяет средства информационных технологий при эксплуатации трансформаторных подстанций и распределительных пунктов», при разработке которого были учтены основные результаты обучения:

1) выпускник должен знать основы методологии расчета режимов работы объектов профессиональной деятельности; принципы построения и работы цифровых систем в электроснабжении;

2) выпускник должен уметь систематизировать статистическую информацию о состоянии систем электроснабжения; квалифицированно 


\section{ЦИФРОВИЗАЦИЯ КАК НОВАЯ ПАРАДИГМА РАЗВИТИЯ: ВЫЗОВЫ, ВОЗМОЖНОСТИ И ПЕРСПЕКТИВЫ}

выбирать наиболее эффективные методы и средства для проектирования цифровых систем управления в электроснабжении;

3) выпускник должен владеть навыками расчета режимов работы систем электроснабжения; навыками работы с программным обеспечением по расчету электрических нагрузок объектов.

Для достижения основных результатов обучения выпускников необходимо предусмотреть комплексный подход к преподаванию дисциплины. Данный подход включает в себя изучение теоретического материала, использование современных тренажеров для повышения уровня практических навыков у студентов при изучении дисциплины и применение прикладных программ для решения задач в электроснабжении.

В рамках изучения материала для освоения цифровых и «сквозных» технологий при изучении дисциплины электроснабжения необходимо рассматривать такие вопросы как: структура цифровой подстанции и ее технологические возможности; наблюдаемость параметров и режимов работы силового оборудования и вторичных систем; цифровой обмен данными между всеми технологическими системами; интеллектуальное адаптивное управление режимом работы силового оборудования с учетом режимов работы прилегающей электрической сети; системы интеллектуального учета электроэнергии ClearView-SCADA; автоматизация электрических сетей; внедрение ГИС топографических средств определения мест повреждения; создание цифровых РЭС; внедрение умных сетей на объектах; влияние автоматизации на надежность электроснабжения и т.д. [2, с. 212]

Основная проблема выпускника при изучении дисциплины электроснабжения - это ознакомление с работой электротехнического персонала на реальном объекте. Для этих целей можно использовать тренажеры. Например, тренажер оперативных переключений TWR-12. Данный тренажер выполнен с применением последних достижений в области искусственного интеллекта.

Кроме того, будущий специалист должен уметь решать задачи с применением программных комплексов то есть создавать модели, анализировать и рассчитывать конструкции электростанций, воздушных линий электропередачи, электрических сетей, систем заземления и других.[3, c. 14] Для решения этих задач используются:

1) Программный комплекс РТП 3. РТП-3 в настоящее время является самым распространенным программным продуктом, позволяющим 
моделировать электрические сети от 0,4 до 220 кВ с целью расчета объемов возникающих в них потерь на основании методических принципов заложенных в Приказе Минэнерго России №326 от 2008 г.

2) Программный комплекс RastrWin3 ТКЗ. Данный комплекс позволяет производить расчеты токов короткого замыкания.

3) Программный комплекс EnergyCS потери. Предназначен для выполнения расчетов потерь электрической энергии при передаче по сетям электроэнергетических систем любой сложности, а также для прогнозирования потерь.

4) Программный комплекс АРМ СРЗА-4. Данный комплекс позволяет вести расчет и выбор защитной аппаратуры средств релейной защиты и автоматики.

5) Программный комплекс Model Studio CS Молниезащита. Производит расчет защитного заземления и молниезащиты.

По нашему мнению такой комплексный подход к изучению дисциплины электроснабжение даст возможность подготовить специалистов такого уровня, который позволит им органично влиться в динамично развивающуюся отрасль национального хозяйства.

\section{Список литературы}

1. https://www.kp.ru/daily/27029/4093659/

2. Петренко Ю.Н. Программное управление технологическими комплексами в энергетике [Электронный ресурс] : учебное пособие / Ю.Н. Петренко, С.О. Новиков, А.А. Гончаров. - Электрон. текстовые данные. - Минск: Вышэйшая школа, 2013. - 408 с.

3. Казакул, Алексей Александрович. Электротехнические расчеты при проектировании ЭЭС с использованием ПВК [Электронный ресурс] : метод. указания по выполнению курс. работы по дисц. "Алгоритмы задач электроэнергетики" / А.А. Казакул ; АмГУ, Эн. ф. - Благовещенск : Изд-во Амур. гос. ун-та, 2014. - 63 с.

(C) М.В. Шевченко, Л.Н. Горбунова, С.Н. Воякин, П.П. Проценко, 2021 